University of Wollongong

Research Online

Faculty of Social Sciences - Papers (Archive) Faculty of Arts, Social Sciences \& Humanities

$1-1-2013$

Infant interest in their mother's face is associated with maternal

psychological health

Rebecca Jones

University of Sheffield

Pauline Slade

University of Sheffield

Olivier Pascalis

Laboratoire de Psychologie et NeuroCognition

Jane S. Herbert

University of Sheffield, herbertj@uow.edu.au

Follow this and additional works at: https://ro.uow.edu.au/sspapers

Part of the Education Commons, and the Social and Behavioral Sciences Commons

Research Online is the open access institutional repository for the University of Wollongong. For further information contact the UOW Library: research-pubs@uow.edu.au 


\title{
Infant interest in their mother's face is associated with maternal psychological health
}

\author{
Abstract \\ Early experience can alter infants' interest in faces in their environment. This study investigated the \\ relationship between maternal psychological health, mother-infant bonding, and infant face interest in a \\ community sample. A visual habituation paradigm was used to independently assess 3.5-month old \\ infants' attention to a photograph of their mother's face and a stranger's face. In this sample of 54 healthy \\ mother-infant pairs, $57 \%$ of mothers $(\mathrm{N}=31)$ reported symptoms of at least one of stress response to \\ trauma, anxiety, or depression. Interest in the mother-face, but not stranger-face, was positively \\ associated with the mother's psychological health. In regression analyses, anxiety and depression \\ predicted $9 \%$ of the variance in looking to the mother-face. Anxiety was the only significant predictor \\ within the model. No direct associations were found between mother-infant bonding and infants' face \\ interest. Taken together, these findings indicate that infant's visual engagement with their mother's face \\ varies with maternal symptoms of emotional distress, even within a community sample.

\section{Disciplines \\ Education | Social and Behavioral Sciences}

\section{Publication Details} \\ Jones, R., Slade, P., Pascalis, O. \& Herbert, J. S. (2013). Infant interest in their mother's face is associated \\ with maternal psychological health. Infant Behavior and Development, 36 (4), 686-693.
}




\title{
Infant interest in their mother's face is associated with maternal psychological health
}

\author{
Rebecca Jones $^{1}$, Pauline Slade ${ }^{1}$, Olivier Pascalis ${ }^{2}$ \& Jane S Herbert ${ }^{1}$ \\ 1-Department of Psychology, University of Sheffield, UK \\ 2- LPNC, Grenoble, France
}

\begin{abstract}
Early experience can alter infants' interest in faces in their environment. This study investigated the relationship between maternal psychological health, mother-infant bonding, and infant face interest in a community sample. A visual habituation paradigm was used to independently assess 3.5-month old infants' attention to a photograph of their mother's face and a stranger's face. In this sample of 54 healthy mother-infant pairs, $57 \%$ of mothers $(\mathrm{N}=31)$ reported symptoms of at least one of Stress Response to Trauma, Anxiety, or Depression. Interest in the mother-face, but not stranger- face, was positively associated with the mother's psychological health. In regression analyses, anxiety and depression predicted $9 \%$ of the variance in looking to the mother-face. Anxiety was the only significant predictor within the model. No direct associations were found between mother-infant bonding and infants' face interest. Taken together, these findings indicate that infant's visual engagement with their mother's face varies with maternal symptoms of emotional distress, even within a community sample.
\end{abstract}

Key words: Learning, Infant, Maternal Wellbeing, Anxiety, Postpartum Depression 
Shortly after birth, infants show a preference for looking at their mother's face compared to the face of a female stranger (Barrera \& Maurer, 1981; Bushnell, Sai, \& Mullin, 1989; Field, Cohen, Garcia, \& Greenberg, 1984; Pascalis, de Schonen, Morton, Deruelle, \& Fabre-Grenet, 1995). A preference for the stranger emerges at around 4-5 months as infants become increasingly interested in novelty (Bartrip, Morton, \& de Schonen, 2001). Whilst considerable attention has been devoted to understanding how infants learn to recognize their mother, individual differences in infants' face interest have rarely been explored. The initial mother-face preference is thought to be important as it may enhance bonding and provide the infant with a reliable source of comfort and affect regulation (Blass \& Camp, 2003). Thus, associations may exist between infant interest in the mother's face, maternal psychological health, and the mother-infant relationship.

Experience with different faces in the visual environment impacts on the development of the face processing system. For example, 3-month-old infants show a visual preference for faces that match the gender of their primary caregiver (Quinn, Yahr, Kuhn, Slater, \& Pascalis, 2002) and for faces of their own ethnic group (e.g., Bar-Haim, Ziv, Lamy, \& Hodes, 2006; Kelly et al., 2005). Infants are proposed to begin life with a general mechanism dedicated to processing faces that subsequently becomes "tuned" to human faces as a direct consequence of the facial input received within the first months of life (Nelson, 2001). According to this account, the infant begins life with a crude and unspecified face representation that is then subject to modification as a result of the category of facial input received. North American infants experience a significantly greater amount of interaction with female individuals relative to male individuals (Rennels \& Davis, 2008), which would explain the female preference typically observed at 3 months of age. In contrast, infants whose primary caregivers are male have a preference for male instead of female faces (Quinn et al., 2002). Thus, differential experience with male and female faces results in a 
spontaneous preference for the more familiar face type. The typical mother-face preference may then be interpreted as a consequence of the amount of time infants have spent with their mother and/or the quality of their face-to-face interactions. The purpose of the current research is to explore potential associations between maternal factors and infants' interest in the face of their mother and a stranger.

Within the general population there is extensive variation in maternal psychological health, with clinical levels of anxiety and depression observed in around 8-18\% of mothers post childbirth (e.g., Cooper, Campbell, Day, Kennerley \& Bond, 1988; Davies, Slade, Wright, \& Stewart, 2008; Scott, Couser, Schilder, O’Hara \& Gorman, 1998). Maternal psychological health impacts on early mother-infant bonding (Carter, Garrity-Rokous, Chazan-Cohen, Little \& Briggs-Gowan, 2001; Stanley, Murray \& Stein, 2004) and is associated with later infant cognitive development, with post-partum depression being related to poorer infant cognitive scores at 18 months of age (Righetti-Veletma, Bousquet \& Manzano, 2003). In addition, a further group of mothers are likely to be affected by subclinical levels of emotional disorders which may impact on her interactions with, or perceptions of, their child.

For some women, childbirth itself can be a traumatic event, even when the result of this experience is a healthy baby. The prevalence of childbirth related post-traumatic stress disorder (PTSD) is reported to be between $1.25 \%$ and 3\% (e.g., Ayers \& Pickering, 2001; Czarnocka \& Slade, 2000; Söderquist, Wijma, \& Wijma, 2006), with up to a third of mothers from a community sample reporting partial post-traumatic stress (PTS) symptoms of intrusive thoughts, avoidance, or hyperarousal (e.g., Maggoni, Margola, Filippi, 2006). Although the prevalence of child-birth related PTS symptoms is usually measured within the first 6 months, some women experience clinically significant levels up to 2 years postpartum (McDonald, Slade, Spiby, \& Illes, 2011). Mothers with full or partial PTSD symptoms at 6 
weeks have also reported viewing their infant as more emotionally demanding and disturbing ("invasive") and less warm than non-symptomatic mothers (Davies et al., 2008). Early post traumatic stress symptoms have also been associated with later parenting distress (McDonald et al., 2011). Given the prevalence of psychological symptoms in mothers postnatally, there is cause to consider the potential associations between maternal psychological health, early infant development and bonding, and infant interest in interacting with his or her mother.

Recently, researchers have begun to examine the effects of maternal depression on infants' mother face interest. These studies have shown that infants of clinically depressed mothers appear to be less responsive to the combined presentation of faces and voices (for review see Field, Diego \& Hernandez-Reif, 2009). For example, maternal depression is associated with increased infant arousal and reduced attention when 3-month-old infants are tested in a live interaction involving a face/voice stimulus (Hernandez-Reif, Field, Diego \& Ruddock, 2006). To date, however, only one study (Hernandez-Reif, Field, Diego \& Largie, 2002) has considered the association between maternal psychological health and infant interest in their mother's face compared to a stranger's face. In this study, 1- to 3-day old infants of mothers experiencing clinical depression showed less interest in their mother's face compared to infants of non-depressed mothers. The conclusions of this study are, however, limited for three key reasons. First, this study used a very small sample size of ten mothers in each of the depressed and control groups. Second, infants were tested at 1- to 3-days of age when mother-infant interactions and bonding remain limited. Third, infant behavior was assessed within the context of the mother-infant interaction and, thus, may have been influenced by maternal responsiveness. The inclusion of verbal interaction with the infant, which may in itself have been affected by maternal mood, was also part of the stimulus presentation and may have guided the infant's visual attention more than the faces. The use of photographed stimuli, as used extensively in the face perception literature (Pascalis et al., 
1995, Bartrip et al., 2001) to assess infant interest in the mother-face, would allow assessment without the confound of mother-infant interaction within the testing session.

The current study investigated the potential association between maternal psychological health, bonding (as measured by maternal perception of their infant), and infant interest in the mother-face and stranger-face within a community sample of mothers and their 3.5 month-old infants. Given that the mother-face represents a special stimulus for the young infant (Blass \& Camp, 2003), and the proposal that maternal symptoms of psychological distress may impact on the mother-infant relationship and on the infant's development or behavior (Ayers \& Pickering, 2001), we predicted that maternal psychological health and bonding would be associated with interest in the mother's face than the stranger's face. Specifically, we predicted that infants would show longer looking at their mother's face if the mother reported no symptoms of psychological distress, than if she reported symptoms of depression, anxiety, PTS symptoms, or lower levels of mother-infant bonding. Based on the assumption that attention to the stranger's face is driven by attraction to novelty (Bartrip et al., 2001), we hypothesized that interest in the stranger face would stay constant, regardless of maternal well-being or the mother-infant relationship.

\section{Method}

\section{Participants}

The final sample consisted of 54 infants (28 male, 26 female) aged 3.5 months (+/- 10 days) and their mothers. Mothers had a mean age of 32.7 years $(\mathrm{SD}=5.35$ years $)$ and were drawn from a community sample recruited from the local maternity ward. No infants were born more than 14 days before their expected due date or had experienced any birth complications. Infants were Caucasian (92\%) and Asian (8\%), and all were from families of moderate to high socio-economic status. An additional 22 infants were tested but not 
included in the final sample due to being excessively fussy or falling asleep during the experimental procedure $(n=20)$, or due to experimenter error $(n=2)$. This attrition rate is consistent with previous studies using visual procedures with this age group (Pascalis et al., 1995; Bartrip et al., 2001).

\section{Stimuli}

The face-stimuli for each infant consisted of a color photograph of their own mother's face paired with a stranger's face (see Figure 1), to use in a sequential presentation procedure. A digital photograph of each mother was taken immediately prior to the study and cropped using Photoshop (Adobe Systems, San Jose, CA) to remove the neck and shoulder detail. Mother's and stranger models were instructed to keep a neutral expression. The photograph was then mounted on a uniform cream background and resized to ensure uniformity (approximately $20 \mathrm{~cm}$ x $20 \mathrm{~cm}$ when projected onto the screen). Strangers' photographs were selected from a laboratory database of female faces, and matched for approximate ethnicity, age, hair color, hair length, and the presence of glasses. Faces were not matched for overall similarity, as the primary measure was attention to the face, not the infant's ability to discriminate between the faces. Indeed, faces were presented sequentially with the variable in question being overall interest in faces, not preferences.

\section{Insert Figure 1 about here}

\section{Maternal Measures}

Maternal psychological health and perception of mother-infant bonding was evaluated using 3 self-report questionnaires. 
Hospital Anxiety and Depression Scale (HADS, Zigmond \& Snaith, 1983)

This 14-item questionnaire measures the extent of symptoms of depression and anxiety experienced over the past week ( 7 questions per scale) on statements such as 'I feel tense' with a choice of 4 answers, 'most of the time' to 'not at all'. The total anxiety and depression scores were scored as; 0-7 'normal', 8-10 'mild' 11-13 'moderate', 14+ 'severe'. In line with clinical usage scores of 8 or above were considered of clinical significance. Internal consistency has a mean of Cronbach's alpha .82 for the anxiety scale, and .83 for the depression scale (Bjelland, Dahl, Haug \& Neckelmann, 2002). The HADS is recommended for assessment of mental health post-childbirth (NICE, Guideline 45, 2007).

Impact of Events Scale (IES, Horowitz, Wilner \& Alvarez, 1979)

This 15-item questionnaire measures the presence and severity of avoidance and intrusion symptoms over the past 7 days relating to a specified stressor -in this instance, childbirth. Past studies investigating mild stress reactions using IES consider scores of 0-8 as 'sub-clinical', 9-25 'mild reaction to trauma', 26-43 'moderate', and 44+ 'severe', with only scores of 26+ seen as clinical levels of Post-Traumatic Stress (Brock, Freeman, \& Cooke, 2006; Williams, Evans, Wilson \& Needham, 2002). Internal reliability ranged from Cronbach's alpha .87 to .92 for intrusions and .84 to .86 for avoidance.

\section{Mothers' Object Relations-Short Form (MORS-SF, Oates \& Gervai, 2003)}

This 14-item questionnaire was developed as a screening tool to identify potential areas of difficulty in the mother-child attachment relationship. It provides a self-reported measure of bonding using a mother's perception of her infant's warmth and invasiveness. . The 'Warmth' scale measures the mother's perceptions about how the infant feels towards her (e.g., “...my baby is affectionate to me...”), The 'Invasion' scale measures the mother's 
perceptions about the baby being seen as intrusive (e.g., “...my baby wants too much attention...". Higher scores (0-35) on each scale indicate greater warmth and invasiveness. The MORS-SF axis items have been shown to possess stable and internally coherent scales (Oates, Gervai, Danis \& Tsaroucha, 2005). Reliability from Cronbach's alpha was .88 and .81 for the two scales respectively.

\section{Procedure}

The purpose of the study was explained to the mother and informed consent was obtained on arrival at the University of XX infant lab. The mother's photograph was taken and processed to create the mother face stimulus. The maternal questionnaires were completed after the infant testing procedure.

Infants were seated on their mother's lap in a darkened sound-attenuating room. Individual face stimuli were back-projected onto a computer screen approximately $60 \mathrm{~cm}$ in front of the infant. Infants saw two presentations of each face, alternating between motherface and stranger-face. The order of presentation (mother or stranger first) was counterbalanced. An infant controlled procedure was used whereby a face was presented for a maximum trial duration of 60 seconds or until the infant looked away for 2 seconds or more (see Horowitz, Paden, Bhana, \& Self, 1978) for the origins of this methodology). The next trial then commenced immediately. If the infant did not initially look to the screen, a rattle was shaken behind the screen to attract attention, but not used again once the infant had visually attended for the first time to each photograph. Total testing time was not longer than 5 minutes.

A camera was positioned above the screen to record the infant's eye movements. The videos were converted into digital format and scored off-line using Videolab which allowed eye movements to be scored in individual frames. The videos were scored double-blind by 
the experimenter. Twenty percent of the videos were also second coded by an independent rater, and inter-rater reliability was $96.7 \%$.

\section{Results}

Two measures of looking time were calculated: time spent looking at the mother's face (mother-face interest), and time spent looking at the stranger's face (stranger-face interest). Initial analyses revealed no effect of infant gender on looking time.

In the initial analysis of overall face interest, infants' mean looking time to the mother and stranger was compared. Mean looking times to mother-face $(M=56 \mathrm{~s}, S D=36 \mathrm{~s})$ and stranger-face $(M=52 \mathrm{~s}, S D=35 \mathrm{~s})$ were not significantly different $(t(53)=0.93, p=0.36$, two tailed). Thus, the overall amount of attention the mother-face and stranger-face is equivalent at 3.5 months of age when the images are presented sequentially. This analysis does not, however, provide information about whether there is variability in attention to the motherface as a function of maternal psychological health or the mother-infant relationship.

To determine whether there were individual differences in maternal psychological health, maternal questionnaires were analyzed. Maternal ratings of their own psychological health are shown in Table 1 . The only variable in the questionnaire data to show significant skew or kurtosis was the measure of stress reaction to trauma using the IES, which was skewed due to a large number of mothers scoring 0 , as could be expected in a community sample. This variable was re-coded into a dichotomous variable for the regression analysis with scores of 8 or under representing no stress reaction to trauma, and scores of 9 or greater representing a mild or above stress reaction to trauma. 
Regression analyses were conducted to investigate the proportion of variance in infant face interest scores that could be accounted for by the maternal factors of mood and perception of infant. Regression analyses were conducted for the two maternal measures used with infant interest to the mother-face and stranger-face entered as dependent variables.

The model incorporating anxiety and depression scores was found to be significant in explaining $9 \%$ of the variance in interest in the mother-face $\left(\mathrm{F}=3.59, \mathrm{R}^{2}=0.09, p<0.05\right)$, with the beta weights indicating only anxiety was a significant contributor $(p<0.05)$ in the motherface model. The model of anxiety and depression was not significant in accounting for the variance in interest in the stranger face $\left(\mathrm{F}=0.39, \mathrm{R}^{2}=0.02, p=0.68\right)$. No other regression analyses were significant, with response to childbirth on the IES and perception of infant (warmth and invasion) on the MORS-SI not predicting infant interest in faces. The scatterplots in Figure 2 show the spread of looking times to mother and stranger-faces in relation to anxiety scores.

\section{Insert Figure 2 about here}

A further set of analyses considered whether infants with mothers showing mild symptoms of anxiety, depression or stress reaction to trauma differed in their looking patterns from infants with mothers reporting no symptoms. Considering the overall presence of symptoms from the HADS and IES, $43 \%$ of mothers showed no symptoms at a mild or above clinically recordable level of anxiety, depression or post-traumatic stress. The highest level of mood symptoms was shown for PTS symptoms with $41 \%$ of mothers $(\mathrm{N}=22)$ showing mild symptoms or above, then anxiety with $32 \%$ of mothers $(\mathrm{N}=17)$ showing mild symptoms or above, followed by depression with $1.9 \%$ of mothers $(\mathrm{N}=1)$ showing mild symptoms or 
above. In combination, $57 \%$ of mothers $(\mathrm{N}=31)$ showed symptoms of at least one of stress reaction to trauma, anxiety or depression.

An analysis of presence or absence of clinical symptoms in association with infant face interest was conducted using a repeated-measures ANCOVA to investigate interest in mother- and stranger-face by symptom group, with co-variate gender. There was an interaction between symptoms and face type $(\mathrm{F}(1,51)=5.29, p<0.05)$. Infants in the maternal symptoms group looked a similar amount to the stranger face $(M=53 \mathrm{~s}, S D=37 \mathrm{~s})$ and to the mother-face $(M=49 \mathrm{~s}, S D=36 \mathrm{~s})$ (see Figure 3$)$. In contrast, infants in the maternal nosymptoms group showed a trend towards looking longer to the mother-face $(M=65 \mathrm{~s}, S D=33 \mathrm{~s})$ than the stranger-face $(M=51 \mathrm{~s}, S D=33 \mathrm{~s})$.

Insert Figure 3 about here

Post-hoc t-tests comparing looking times to the mother and stranger within group (i.e. symptoms of non-symptoms) were significant for the no-symptoms $(\mathrm{t}=0.03, \mathrm{p}<.0 .05)$ but not for the symptoms group $(\mathrm{t}=0.35$, n.s. $)$ No other effects were found.

\section{Discussion}

Infants' mother-face interest, but not infants' general perceptual interest in faces, is associated with maternal psychological health. Consistent with our hypotheses, infants of mothers with symptoms of psychological distress (mild or above) showed no differences in looking towards their mother's face compared to a stranger's face. In contrast, infants whose mothers showed no symptoms spent a longer proportion of time looking to their mother's face, a finding that is consistent with the mother-face preference traditionally observed in the 
face processing literature with infants in the first months of life (Barrera \& Maurer, 1981; Bushnell et al., 1989; Field et al., 1984).

What might account for the association between maternal psychological health and infant interest in their mother's face? Previous social interaction with the stimulus has been identified as a factor that can affect the expression of the infant's recognition response in a visual preference task. In general, infants prefer to look at a stimulus previously encountered within the context of a positive social interaction than at a new stimulus (Gross, Hayne, Herbert, \& Sowerby, 2002; Brown, Robinson, Herbert, \& Pascalis, 2006; Nachman, Stern \& Best, 1986).There is also some qualitative evidence to suggest that woman who have experienced a traumatic birth experience may actively seek to avoid, or show resentment for, their infant as the cause of the trauma (Ballard, Stanley, \& Brockington, 1995; Allen, 1998). Thus, stressful early experiences in the mother-child relationship may impact on the way a mother relates to her infant, and the way the infant responds to his or her mother. Infants may become less interested in attending to the mother face if maternal well-being has impacted on the quality or quality of early social interactions.

It is possible that the relationship between maternal psychological health and infant face-interest observed in the current study may also relate specifically to the use of a neutral expression in the stimulus, which may be perceived by infants as similar to a still-face. A 'still-face', as used in infant studies, is the expression held by an adult to an infant where they keep a neutral and still expression and stop interacting. It has been found that infants whose mothers perceive them negatively, may react more negatively themselves in the still-face paradigm (Rosenblum, McDonaugh, Muzik, Miller \& Sameroff, 2002), although this result was not found to be directly linked to maternal psychological health. The potential impact of the neutral face could not be argued to generalize to all face-stimuli, as infants whose mothers showed clinical symptoms in the present study did not respond very differently from 
the non-symptom group to the neutral face of the stranger, in fact they showed slightly more interest, suggesting that a neutral face in itself is not aversive, possibly only the neutral mother-face.

Alternatively, the mother's neutral expression may be more familiar to infants of mothers with poorer psychological health and therefore they find the face less interesting. Infants in the non-symptom group may also find the expression novel in their mother and show greater interest, hence showing a novelty preference, as in previous research (Schwarzer \& Zauner, 2003). Recently, 3-month-old infants from non-depressed mothers were found to look longer at a video of a woman expressing happy emotion compared to speaking in a monotone voice and exhibiting flat facial expressions. In contrast, infants of depressed mothers took longer to habituate to the video expressing happy emotion (Hernandez-Reif, Field, Diego, Vera, \& Pickens, 2006). Thus, there may be a relationship between infant's familiarity with expressions/emotions and their perceptual interest in those emotions expressed by others.

Of interest to the face-perception literature is that, overall, the 3.5-month old infants in this study did not look longer to the mother's face in comparison to the time they spent looking at the stranger's face. This could be the result of the infants approaching 4-5 months of age, when the mother face preference is replaced by a stranger face preference (Bartrip et al., 2001). It is important to note, however, that the current study assessed interest to each face presented sequentially, not presented together in a preferential looking procedure. Thus, our results do not present a contradiction to previous findings, but rather may be indicative of general face interest to the mother and a female stranger's being fairly equal at 3.5-months as opposed to a mother-face preference when an infant is forced to choose between their mother and a stranger. This would fit with the finding that infants are generally interested in faces as social stimuli (Johnson, Dziurawiec, Ellis \& Morton, 1991). Individual differences do exist, 
however, as highlighted by our study, and are of interest in understanding early infant perceptual development. It is possible that the lack of overall group differences may in part be explained by the lack of difference in looking to mother and stranger in the clinical symptoms group, however it must be noted that a community sample was used and may not differ in levels of symptoms from previous community samples used in face interest studies.

Of the maternal factors tested in the current study, anxiety and depression scores were found to predict $9 \%$ variance of looking to the mother-face. Anxiety was the only significant predictor within the model: subsequent correlations indicated that increases in maternal anxiety symptoms were associated with decreased infant looking times to the mother-face. It was notable that within our community sample there were higher numbers of mothers reporting anxiety symptoms than depressions symptoms where only 1 mother reported clinically notable level of depression. It is possible that maternal depression would also predict infant looking times to their mother's face if higher numbers of mothers were present with symptoms of depression.

The measure of bonding, involving maternal reports of warmth and intrusion of their infant, and the measure of response to trauma were not directly associated with infant interest in the mother-face or stranger-face. However maternal psychological health was associated with bonding, with negative associations found with anxiety and depression. Consistent with previous research (Davies et al., 2008), our findings highlight the importance of considering bonding in relation to psychological health. However, maternal perception of bonding and infant face-interest were not found to be directly related in the present study, though previous studies have found an association and this may reflect the sample and measures selected.

A final point to consider is that these findings raise an important question about the effects of the environment on the early face processing system. Given that environmental factors shape infant face recognition abilities (Kelly et al., 2005; Pascalis et al., 2002; Quinn 
et al., 2002), could maternal psychological health impact on the infants' developing face processing system? A recent study suggests that depression symptoms may disrupt the pregnant women's visual attention to emotional infant faces. Non-depressed pregnant woman (average gestation 11 weeks) look for longer at photos of distressed compared to nondistressed infants, while woman with depressive symptoms showed no such attentional bias (Pearson, Cooper, Penton-Voak, Lightman, \& Evans; 2010). If similar maternal attention patterns are demonstrated following birth, it is possible that infants with mothers who are experiencing depression symptoms may receive a different experience with faces, or the combination of faces and emotions, early in development. Potentially, the early face processing system might become tuned differently in the infants of non-depressed mothers. Although this remains speculative, further research is needed to examine whether infants from depressed mothers show the traditional female preference when presented with male and female faces (Quinn et al., 2002), or whether they may be better at recognizing female compared to male faces.

Taken together, these findings extend previously reported associations between perceptual preferences and maternal psychological health in newborn infants (HernandezReif et al., 2002; 2006) and associations between cognitive ability and maternal psychological health in older infants (Murray, Fiori-Cowley, Hooper, \& Cooper, 1996; Righetti-Veletma et al., 2003; Cornish, McMahon, Ungerer, Barnett, Kowalenko, \& Tennant, 2005). Small individual differences in maternal psychological health experienced early in infant development impact on infant's visual interest in the mother's face, even within community samples. 


\section{$\underline{\text { Authors' Notes }}$}

This research compromised a portion of the DClin dissertation of Rebecca Jones, and was completed under the supervision of Pauline Slade and Jane Herbert. The authors would like to thank the infants and parents who participated in this project.

Corresponding author: Dr Jane S. Herbert, Department of Psychology, University of Sheffield, Sheffield, S10 2TN, UK. Tel: +44 (0)114 222 6512, Fax: +44 (0)114 276 6515, email: j.s.herbert@sheffield.ac.uk 


\section{References}

Allen, S. (1998). A qualitative analysis of the process, mediating variables and impact of traumatic childbirth. Journal of Reproductive and Infant Psychology, 16, 107-131.

Ayers, S., \& Pickering, A.D. (2001). Do women get posttraumatic stress disorder as a result of childbirth? A prospective study of incidence. Birth, 28, 111-118.

Ballard, C.G., Stanley, A.K., \& Brockington. I.F. (1995). Post-traumatic stress dosprder (PTSD) after childbirth. British Journal of Psychiatry, 166, 525-528.

Bar-Haim, Y., Ziv, T., Lamy, D. \& Hodes, R.M. (2006). Nature and nurture in ownrace face processing. Psychological Science, 17, 159-163.

Barrera, M.E. \& Maurer, D. (1981). Discrimination of strangers by the three-monthold. Child Development, 52, 558-563.

Bartrip, J., Morton, J. \& de Schonen, S. (2001). Responses to mother's face in 3-week to 5-month-old infants. British Journal of Developmental Psychology, 19, 219-232.

Bjelland, I., Dahl, A.A., Haug, T.T., \& Necklemann, D. (2002). The validity of the Hospital Anxiety and Depression Scale. An updated literature review. Journal of Psychosomatic Research, 52, 69-77.

Blass, E.M. \& Camp, C.A. (2003). Biological bases of face preference in 6-week-old infants. Developmental Science, 6, 524-536.

Brock, C., Freeman, D. \& Cooke, A. (2006). Identifying potential predictors of traumatic reactions to psychotic episodes. British Journal of Clinical Psychology, 4, 545-559.

Brown, A., Robinson, A., Herbert, J.S. \& Pascalis, O. (2006) Age and emotional salience of stimuli alter the expression of visual recognition memory. Current Psychology Letters, 20, N³.

Bushnell, I., Sai F. \& Mullin, J. (1989). Neonatal recognition of the mother's face, British Journal of Developmental Psychology, 7, 3-15. 
Carter, A.S., Garrity-Rokous, J.D., Cahzan-Cohen, R., Little, C. \& Briggs-Gowan, M.J. (2001). Maternal depression and co-morbidity: Predicting early parenting, attachment security, and toddler social-emotional problems and competencies. Journal of the American Academy of Child and Adolescent Psychiatry, 40, 18-26.

Cooper, P.J., Campbell, E.A., Day, A., Kennerley, H. \& Bond, A. (1988). Nonpsychotic psychiatric disorder after childbirth. A prospective study of prevalence, incidence, course and nature. The British Journal of Psychiatry, 152, 799-806.

Cornish, A., McMahon, C., Ungerer, J., Barnett, B., Kowalenko, N., Tennant, C. (2005). Postnatal depression and infant cognitive development: The impact of depression chronicity and infant gender. Infant Behavior \& Development, 28, 407-417.

Czarnocka, J., \& Slade, P. (2000). Prevalence and predictors of post-traumatic stress symptoms following childbirth. British Journal of Clinical Psychology, 39, 15-51.

Davies, J., Slade. P., Wright, I. \& Stewart, P. (2008). Posttraumatic stress symptoms following childbirth and the early mother-infant relationship. Infant Mental Health Journal, $29,537-554$.

Field T.M., Cohen, D., Garcia, R. \& Greenberg, R. (1984). Mother-stranger face discrimination by the newborn. Infant Behavior \& Development, 7, 19-25

Field, T., Diego, M., \& Hernandez-Reif, M. (2009). Infants of depressed mothers are less responsive to faces and voices. Infant Behavior \& Development, 32, 239-244.

Gross, J., Hayne, H., Herbert, J., \& Sowerby, P. (2002). Measuring infant memory: Does the ruler matter? Developmental Psychobiology, 40, 183-192.

Hernandez-Reif, M., Field, T., Diego, M. \& Largie, S. (2002). Depressed mother's newborns show longer habituation and fail to show face/voice preference. Infant Mental Health Journal, 23, 643-653. 
Hernandez-Reif, M., Field, T., Diego M., \& Ruddock, M. (2006). Greater arousal and lesser attention by neonates of depressed vs non-depressed mothers on the Brazelton Neonatal Behavioral Assessment Scale. Infant Behavior \& Development, 29, 594-598.

Hernandez-Reif, M., Field, T., Diego, M., Vera, Y. \& Pickens, J. (2006). Happy faces are habituated more slowly by infants of depressed mothers. Infant Behavior \& Development, $29,131-135$.

Horowitz, F.D., Paden, L., Bhana, K. \& Self, P. (1972). An infant-control procedure for studying infant visual fixations. Developmental Psychology, 7, 90.

Horowitz, M., Wilner, N. \& Alvarez, W. (1979). The Impact of Event Scale: A measure of subjective stress. Psychosomatic Medicine, 41, 209-218.

Johnson, M. H., Dziurawiec, S., Ellis, H. D. \& Morton, J. (1991). Newborns’ preferential tracking of face-like stimuli and its subsequent decline. Cognition. 40, 1-19.

Kelly, D. J., Quinn, P. C., Slater, A. M., Lee, K., Gibson, A., Smith, M., Ge, L., \& Pascalis, O. (2005). Three-month-olds, but not newborns, prefer own-race faces. Developmental Science, 8, F31-F36.

McDonald, S., Slade, P., Spiby, H., \& Illes, J., (2011). Post-traumatic stress symptoms, parenting stress and mother-child relationships following childbirth and at 2 years postpartum. Journal of Psychosomatic Obstetrics \& Gynecology, 32, 141-146.

Maggoni, C., Margola, D., \& Filippi, F. (2006). PTSD, risk factors, and expectations among women having a baby: A two-wave longitudinal study. Journal of Psychosomatic Obstetrics \& Gynecology, 27, 81-90.

Murray, L., Fiori-Cowley, A., Hooper, R., \& Cooper, P. (1996). The impact of postnatal depression on associated adversity on early mother-infant interactions and later infant outcome. Child Development, 67, 2512-2526. 
Nachman, P. A., Stern, D. N., \& Best, C. (1986). Affective Reactions to Stimuli and Infant's Preferences for Novelty and Familiarity. Journal of the American Academy of Child Psychiatry, 25, 801-804.

National Institute for Health and Clinical Excellence. Developed by the National Collaboration Centre for Mental Health. (2007) Antenatal and postnatal mental health. Clinical management and service guidance. NICE Guideline 45.

Nelson, C.A. (2001). The development and neural bases of face recognition. Infant \& Child Development, 10, 3-18.

Oates, J. \& Gervai, J. (2003) 'Mothers' Object Relations Scales', poster presented at the XIth European Conference on Developmental Psychology, Milan, Italy.

Oates, J.M., Gervai, J., Danis, I., \& Tsaroucha, A. (2005). Validation studies of the Mothers Object Relations Scales Short Form (MORS-SF). Poster presented at the XIIth European Conference on Developmental Psychology, La Laguna, Tenerife, Spain.

Pascalis, O., de Schonen, S., Morton, J., Deruelle, C. \& Fabre-Grenet, M. (1995). Mother's face recognition by neonates: a replication and an extension. Infant Behavior \& Development. 18, 79-85.

Pearson, R.M., Cooper, R.M., Penton-Voak, I.S., Lightman, S.L. \& Evans, J. (2010). Depressive symptoms in early pregnancy disrupt attentional processing of infant emotion. Psychological Medicine, 40, 621-631.

Quinn, P.C., Yahr, J., Kuhn, A., Slater, A.M. \& Pascalis, O. (2002). Representation of the gender of human faces by infants: a preference for female. Perception, 31, 1109-1121.

Rennels, J. L., \& Davis, R.E. (2008). Facial experience during the first year. Infant Behavior \& Development, 31, 665-678. 
Righetti-Veletma, M., Bousquet, A. \& Manazo, J. (2003). Impact of postpartum depressive symptoms on mother and her 18-month-old infant. European Child and Adolescent Psychiatry, 12, 75-83.

Rosenblum, K.L., McDonaugh, S., Muzik, M., Miller, A. \& Sameroff, A. (2002). Maternal representations of the infant: associations with infant responses to the still face. Child Development, 73, 999-1015.

Schwarzer, G. \& Zauner, N. (2003). Face processing in 8-month-old infants: evidence for configural and analytical processing. Vision Research, 43, 2783-2793.

Scott, S., Couser, G., Schilder, K., O’Hara, M.W., \& Gorman, L. (1998). Postpartum anxiety and depression: Onset and comorbidity in a community sample. The Journal of Nervous and Mental Disease, 186, 420-424.

Söderquist, J., Wijma, B., \& Wijma, K. (2006). The longitudinal course of posttraumatic stress after childbirth. Journal of Psychosomatic Obstetrics \& Gynecology, 27, 113-119.

Stanley, C., Murray, L. \& Stein, A. (2004). The effect of postnatal depression on the mother-infant interaction, infant response to the still-face perturbation, and task performance on an instrumental learning task. Development and Psychopathology, 16, 1-18.

Williams, W.H., Evans, J.J., Wilson, B.A. \& Needham, P. (2002). Prevalence of posttraumatic stress disorder symptoms after severe brain injury in a representative community sample. Brain Injury, 8, 673-679.

Zigmond, A.S., Snaith, R.P. (1983). The Hospital Anxiety and Depression Scale. Acta Psychiatrica Scandinavica, 67, 361-370. 
Table 1

Mean score reported by mothers on each of the psychological health questionnaires

\begin{tabular}{lccc} 
Questionnaire & Mean & SD & $\begin{array}{l}\text { Range } \\
\text { (min-max) }\end{array}$ \\
& & & $0-17$ \\
\hline Anxiety (HADS) & 5.65 & 3.35 & $0-8$ \\
Depression (HADS) & 3.31 & 2.20 & $0-55$ \\
Stress reaction to childbirth (IES) & 11.67 & 13.99 & $10-35$ \\
Warmth (MORS-SF) & 26.89 & 4.53 & $1-19$ \\
Invasion (MORS-SF) & 7.06 & 4.57 & \\
\hline
\end{tabular}


Figure 1

Example of a mother and matched stranger face image

Mother

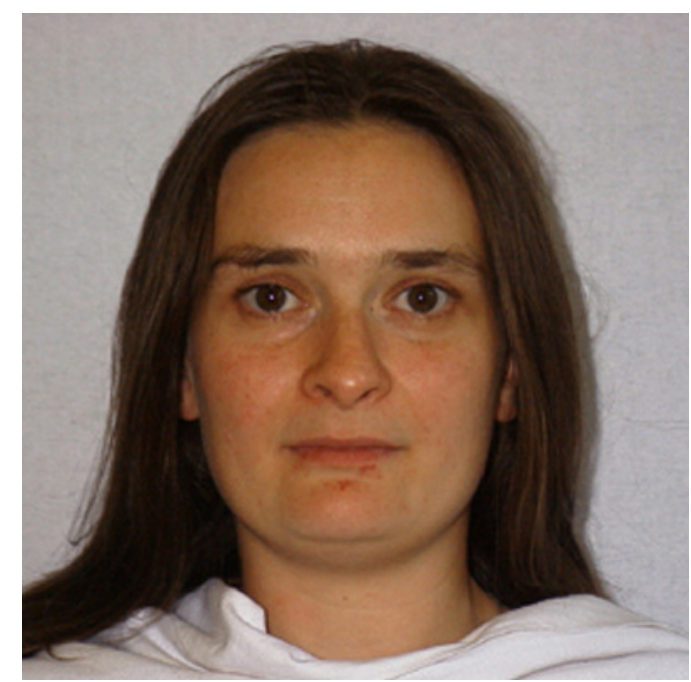

Stranger

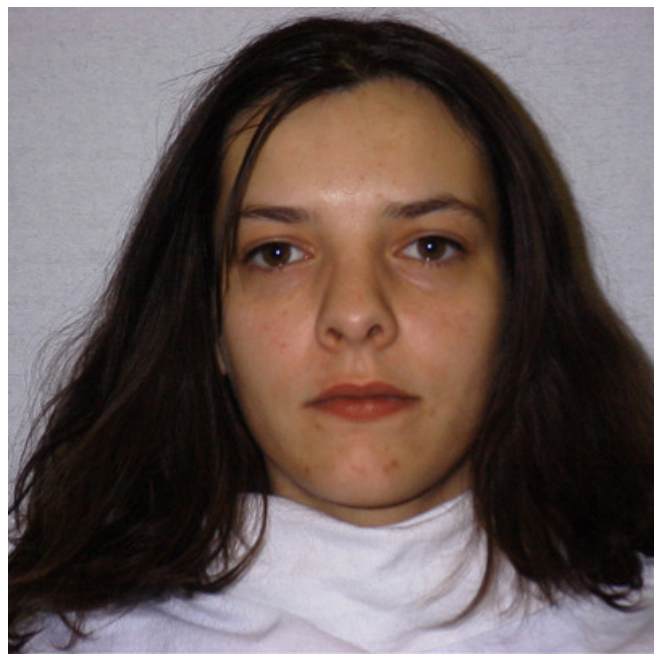


Figure 2

Maternal anxiety scores in relation to infant looking times to the a) mother and b) stranger face

a)

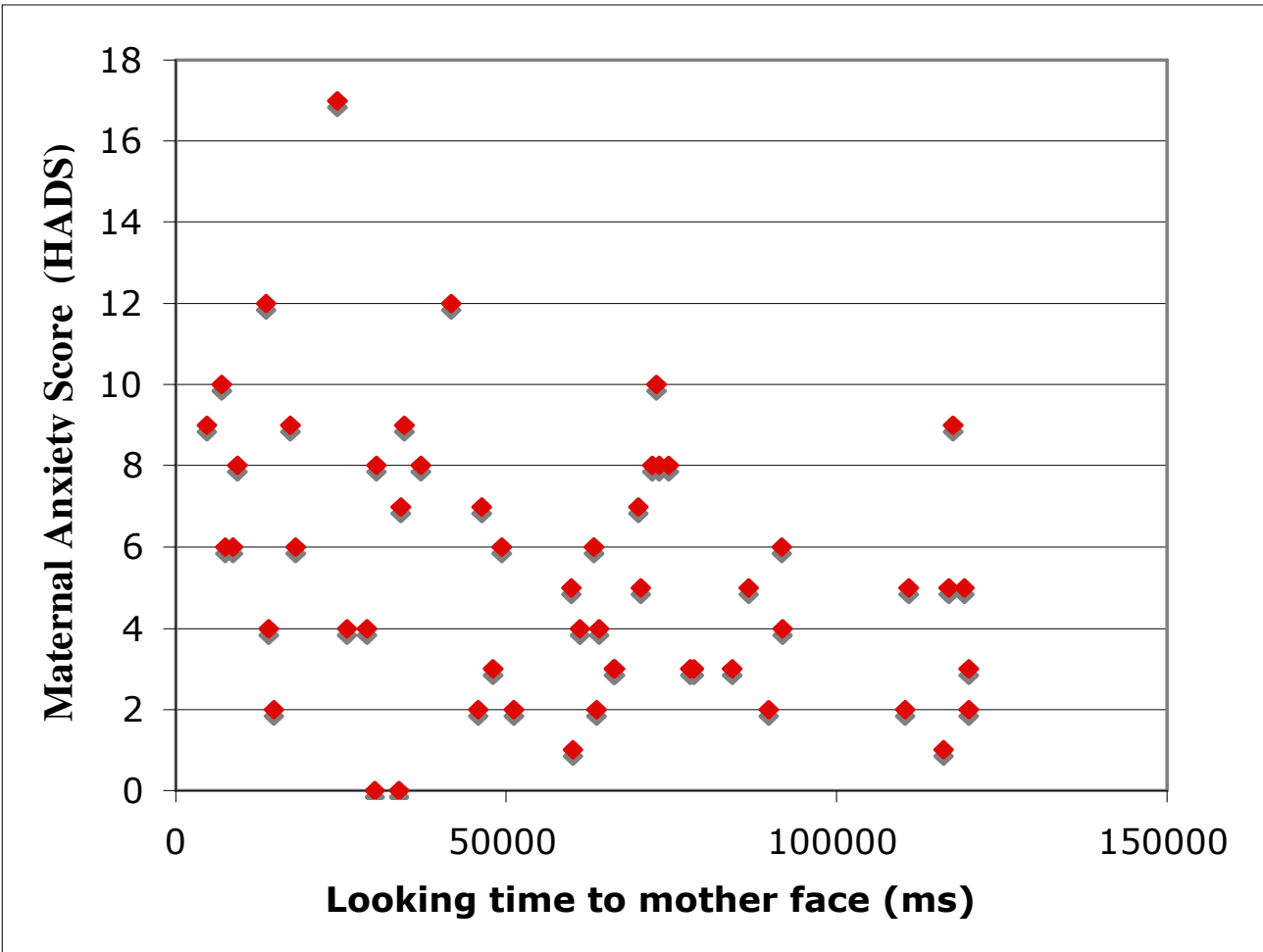

b)

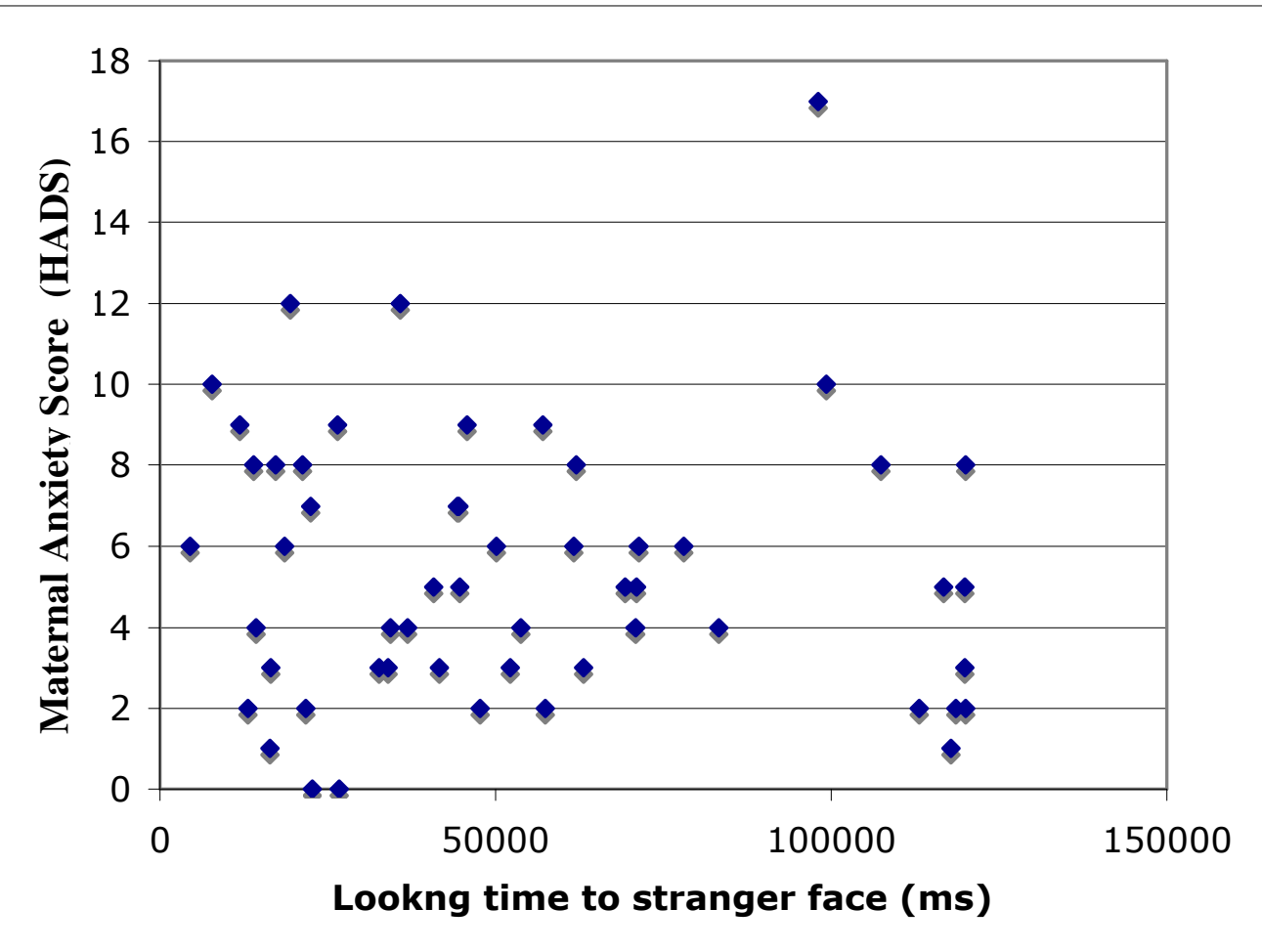


Figure 3

Mean infant looking times (+/- 1 S.E.) to the Mother and Stranger face

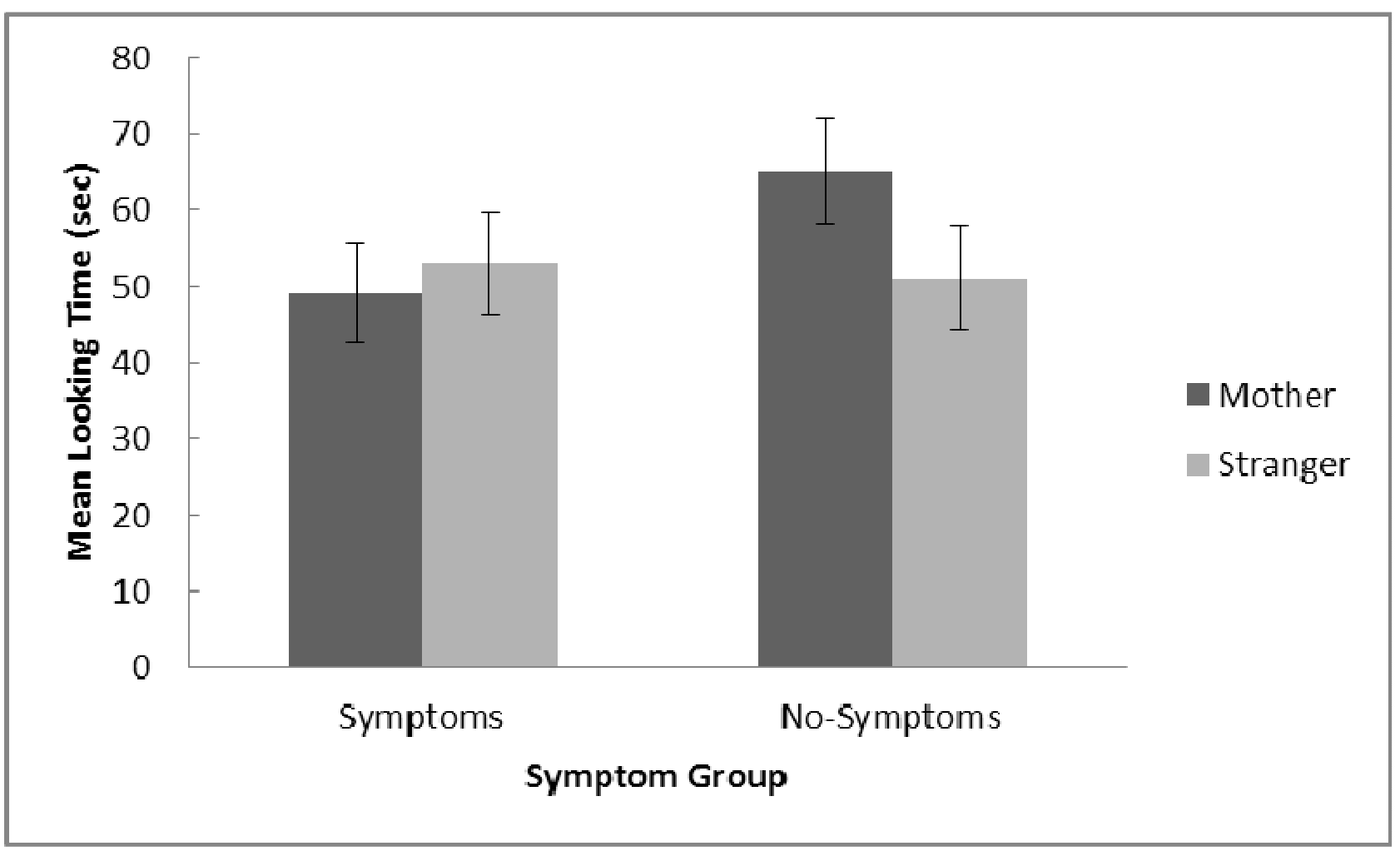

